\title{
Number of Negative Points: A novel method for predicting radiosensitivity in head and neck tumor cell lines
}

\author{
LOVISA FARNEBO ${ }^{1}$, FREDRIK JERHAMMAR ${ }^{1}$, LINDA VAINIKKA ${ }^{1}$, \\ REIDAR GRÉNMAN ${ }^{2}$, LENA NORBERG-SPAAK ${ }^{1}$ and KARIN ROBERG ${ }^{1}$ \\ ${ }^{1}$ Division of Otorhinolaryngology, University Hospital, SE-58185 Linköping, Sweden; ${ }^{2}$ Department of Otorhinolaryngology, \\ Head and Neck Surgery, Central Hospital and University of Turku and Medical Biochemistry, University of Turku, Finland
}

Received March 26, 2008; Accepted April 29, 2008

DOI: 10.3892/or_00000028

\begin{abstract}
The present study was aimed at establishing a method that combines multiple factors of protein and genetic changes that enables prediction of radiosensitivity in the head and neck squamous cell carcinoma (HNSCC) cell lines. In nine HNSCC cell lines, the quantity of protein expression and the type of genetic alterations were translated into a point system, called the Number of Negative Points. The expression of 14 proteins involved in growth control and/or apoptosis was quantified using a densitometric assessment of Western blots. The blots were adjusted to actin and standardised to normal oral keratinocytes classifying them into four groups depending on the amount of protein expressed (0-3 points). Mutations of the p53 gene were classified into three groups and each mutation was given one point. Since the cell lines each had a known intrinsic radiosensitivity, a multivariate statistical calculation could then be performed to select for the combination of factors having the strongest correlation to radiosensitivity. The strongest correlation of the investigated factors was the combination of epidermal growth factor receptor, survivin and splice site/missense p53 mutations $(R=0.990$ and $\mathrm{P}<0.0001)$. No single factor had a significant correlation to the intrinsic radiosensitivity. Since a significant correlation to the intrinsic radiosensitivity was achieved only when two or more factors were combined, we conclude that a method such as the Number of Negative Points is necessary for prediction of treatment response. We present a novel method to combine factors which enables the prediction of radiosensitivity of HNSCC cell lines.
\end{abstract}

\section{Introduction}

The primary mode of treatment in locally advanced squamous cell carcinoma of the head and neck (HNSCC) involves a

Correspondence to: Dr Karin Roberg, Division of Otorhinolaryngology, University Hospital, SE-58185 Linköping, Sweden E-mail: karin.roberg@inr.liu.se

Key words: predictive markers, p53, epidermal growth factor receptor, survivin, squamous cell carcinoma combination of radiotherapy and surgery or definitive chemoirradiation. Radioresistance and local carcinoma recurrences are significant problems during and after radiotherapy. Visual inspection and palpation are still the most common methods used to detect oral and oropharyngeal squamous cell carcinomas. Histological tumor grade is often of limited prognostic value, and no clear correlation has been found between grade, tumor size and radiosensitivity (1). Therefore there is a paramount need for new predictive markers that can be complementary to the conventional pathological criteria of today. New technologies like protein and DNA microarrays are beginning to provide a clearer picture of protein and genomic alterations associated with treatment sensitivity and tumor progression. Lothaire et al stated that few clinical studies have shown a correlation to prognosis (2) and therefore there is a great need for new systems to predict treatment response.

Most cancers show alterations in multiple genes that encode proteins involved in the regulation of growth control and apoptosis, e.g. the tumor suppressor gene p53, members of the Bcl-2 family and inhibitor of apoptotic proteins (IAPs). The p53 protein takes part in radiation response and is capable of either arresting the cell cycle or inducing apoptosis in a dose-dependent manner (3). Deregulated expression of proteins controlling apoptosis may suppress the apoptotic deletion of cells that normally follows upon DNA damage. Decreased radiosensitivity is seen in tumor cells with functionally defective mutant p53 protein (3). The same is observed in tumor cells with an overexpression of the antiapoptotic protein $\mathrm{Bcl}-2$ as well as decreased expression of pro-apoptotic members of the Bcl-2 family e.g., Bax, Bad, Bak and PUMA $(4,5)$. PUMA has two pathways to induce apoptosis, one p53-dependent and the other p53-independent. Yu et al have shown that PUMA enhanced the effect of both chemotherapeutic agents and radiation therapy in lung cancer cells (6). The epidermal growth factor receptor (EGFR) is commonly overexpressed in human epithelial cancers and influences cell division, migration, adhesion, differentiation and apoptosis through a tyrosine kinase pathway. In HNSCC its overexpression has been shown to correlate with a more aggressive malignancy resulting in poor clinical outcome $(7,8)$. Moreover, Hitt et al showed that factors such as tumor location in the oral cavity, moderate-to-high EGFR staining and p53 expression, were independent prognostic factors of a shorter disease-free survival (9). 
Table I. Tumor characteristics and intrinsic radiation sensitivity.

\begin{tabular}{lcclclc}
\hline Cell line & Sex & Age (years) & Primary tumor location & $\mathrm{TNM}^{\mathrm{a}}$ & Specimen site & AUC (IR) \\
\hline UT-SCC-24A & $\mathrm{M}$ & 41 & Mobile tongue & $\mathrm{T}_{2} \mathrm{~N}_{0} \mathrm{M}_{0}$ & Tongue & $2.6 \pm 0.3$ \\
UT-SCC-77 & $\mathrm{M}$ & 50 & Mobile tongue & $\mathrm{T}_{1} \mathrm{~N}_{0} \mathrm{M}_{0}$ & Neck & $2.5 \pm 0.2$ \\
UT-SCC-33 & $\mathrm{F}$ & 86 & Gingiva of mandible & $\mathrm{T}_{2} \mathrm{~N}_{0} \mathrm{M}_{0}$ & Gingival of mandible & $2.3 \pm 0.2$ \\
UT-SCC-34 & $\mathrm{M}$ & 63 & Supraglottic larynx & $\mathrm{T}_{4} \mathrm{~N}_{0} \mathrm{M}_{0}$ & Supraglottic larynx & $2.1 \pm 0.1$ \\
UT-SCC-12A & $\mathrm{F}$ & 81 & Skin of the nose & $\mathrm{T}_{2} \mathrm{~N}_{0} \mathrm{M}_{0}$ & Skin & $2.1 \pm 0.1$ \\
UT-SCC-2 & $\mathrm{M}$ & 60 & Floor of the mouth & $\mathrm{T}_{4} \mathrm{~N}_{1} \mathrm{M}_{0}$ & Floor of the mouth & $1.8 \pm 0.2$ \\
UT-SCC-19A & $\mathrm{M}$ & 44 & Glottic larynx & $\mathrm{T}_{4} \mathrm{~N}_{0} \mathrm{M}_{0}$ & Larynx & $1.7 \pm 0.1$ \\
UT-SCC-23 & $\mathrm{M}$ & 66 & Transglottic larynx & $\mathrm{T}_{3} \mathrm{~N}_{0} \mathrm{M}_{0}$ & Larynx & $1.6 \pm 0.1$ \\
UT-SCC-9 & $\mathrm{M}$ & 81 & Glottic larynx & $\mathrm{T}_{2} \mathrm{~N}_{1} \mathrm{M}_{0}$ & Neck & $1.4 \pm 0.1$ \\
\hline
\end{tabular}

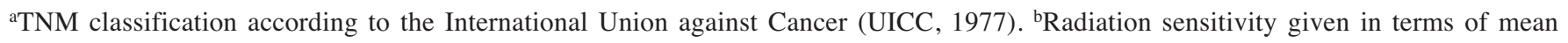
inactivation dose (AUC, area under curve). Previously reported by Pekkola-Heino et al (18) and Erjala et al (29).

Increased expression of cyclooxygenase-2 (COX-2) has been reported in many organ cancers, including those of the head and neck. COX-2 is an inducible enzyme, which can be stimulated by oncogenes and tumor promoters during tumor development (10). Moreover, it has been shown to have a number of cellular effects such as a reduced susceptibility to apoptosis $(11,12)$.

IAPs are crucial regulators of caspases, a family of cystein proteases central for cellular degradation during apoptosis $(7,13)$. Survivin is a recently characterized IAP and high expression of this protein has been associated with inhibition of apoptosis (14). Survivin is undetectable in terminally differentiated adult tissue but becomes notably expressed in several common human cancers (14). Recently, Lo Muzio et al showed that survivin expression may identify cases of oral squamous cell carcinomas with a more aggressive and invasive phenotype (15). Heat shock protein 70 (Hsp70), cyclin D1 and Smad4 are other proteins that have been shown to be involved in tumorigenesis, growth inhibition and/or apoptosis $(16,17)$ and thus they are included in this study.

Taken together, many proteins have been shown to have an impact on the radiosensitivity in HNSCC but it has been difficult to find a significant correlation between expression of a single protein and the outcome of radiotherapy. Therefore, the present study was undertaken to evaluate the possibility of using combinations of multiple factors to predict the intrinsic radiosensitivity of HNSCC cell lines. Fourteen proteins and p53 mutations were selected from the literature because they have been shown to have impact on treatment sensitivity. We wanted a method in which both changes in protein expression and genetic alterations could be included in the same system to predict radiosensitivity. Therefore the Number of Negative Points (NNP) system was created and for the first time we present a novel method for predicting radiosensitivity based on results from nine HNSCC cell lines.

\section{Materials and methods}

Cells and culture conditions. Nine recently established HNSCC cell lines were selected for this study to represent different parts of the in vitro radiosensitivity spectrum (Table I). The average intrinsic radiosensitivity (IR), measured with a 96-well clonogenic assay plate in a large panel of HNSCC cell lines was 1.9 for head and neck cancer of all sites (18). The cells were cultured in Dulbecco's modified Eagle's medium, supplemented with $2 \mathrm{mM}$ glutamine, $1 \%$ non-essential amino acids, $100 \mathrm{IU} / \mathrm{ml}$ penicillin-G, $50 \mu \mathrm{g} / \mathrm{ml}$ streptomycin and $10 \%$ fetal bovine serum (all from Gibco, Paisly, UK). The cells were incubated in humidified air with $5 \% \mathrm{CO}_{2}$ at $37^{\circ} \mathrm{C}$ and subcultured once a week.

Normal oral human keratinocytes (NOK) were cultured as previously described (19). Biopsies were harvested during benign surgery in the oral cavity, mostly tonsillectomies and contained non-keratinized squamous cell epithelium (approved by the Linköping University ethics committee). Primary keratinocyte cultures were derived from trypsin-digested tissue using growth medium (Keratinocyte-SFM; Gibco, Invitrogen Corp.) supplemented with antibiotics solution (penicillin $100 \mu / \mathrm{ml}$, streptomycin $100 \mu \mathrm{g} / \mathrm{ml}$ ) and culture flasks pre-coated with fibronectin and collagen. Medium was replaced at three day intervals, and the cultures were subcultured at about $75 \%$ confluence using $0.25 \%$ trypsin and $0.02 \%$ EDTA. Cultures in passage 2 and 3 were used for the analyses.

Irradition, clonogenic assay and data analysis. The cells were grown to midlogarithmic phase and fed with fresh medium $24 \mathrm{~h}$ before the experiments. The 96 -well plate clonogenic assay was performed as previously described $(18,20,21)$. In brief, the cells were harvested with trypsin/EDTA, counted and diluted to a stock solution. The number of cells plated per well was adjusted according to the plating efficiency of each cell line. After plating, the cells were allowed to attach for $24 \mathrm{~h}$ before irradiation.

The cells were irradiated in 96-well culture plates with $4 \mathrm{MeV}$ photons generated by a linear accelator (Clinac 4/100, Varian, USA); delivering a dose-rate of $2.0 \mathrm{~Gy} / \mathrm{min}$. After incubating the plates for 4 weeks, the number of positive wells was counted using a phase-contrast microscope. Wells with colonies consisting of at least 32 cells were considered as positive. 
Survival data as a function of radiation dose were fitted by a linear quadric equation, and the area under curve (AUC) was obtained by numerical integration (22). For each cell line a minimum of three experiments was performed.

Selection of proteins. The 14 proteins selected in this study were chosen among many potentially interesting factors affecting radiosensitivity. Publications in the literature and our own previous work indicate that the chosen proteins seem to be of particular interest in correlation to radiosensitivity (23).

Western blot analysis. Cells were washed in phosphatebuffered saline (PBS) and lysed in $63 \mathrm{mM}$ Tris-HCl buffer (pH 6.8) containing 10\% glycerol, $2 \%$ SDS, 5\% 2-mercaptoethanol and $0.05 \%$ bromophenol blue (all from Sigma, St. Louis, MO). The protein concentration was determined (24), and $100 \mu \mathrm{g}$ aliquots were separated by $15 \%$ or $4-20 \%$ SDSPAGE (Bio-Rad Laboratories, Hercules, CA USA). Proteins were transferred onto a nitrocellulose membrane (pore size $0.45 \mu \mathrm{m}$; Bio-Rad Laboratories), which was subsequently blocked for $90 \mathrm{~min}$ at room temperature in Tris-buffered saline (TBS; $50 \mathrm{mM}$ Tris and $0.15 \mathrm{M} \mathrm{NaCl}, \mathrm{pH} 7.5$ ) containing $5 \%$ skimmed milk and $0.1 \%$ Tween-20 (Sigma). After washing in TBS, the membranes were incubated with a mouse antiBcl-2 (dilution 1:1000; M0887, Dako, Älvsjö, Sweden), a mouse anti-Bax (1:500; 610983, BD Biosciences, Le Pont de Claix, France), a mouse anti-Bcl- $\mathrm{x}_{\mathrm{L}}(1: 200$; sc-8392), a mouse anti-Bad (1:200; sc-8044), a mouse anti-Bak (1:200; sc-7873), a mouse anti-survivin (1:200; sc-17779), a mouse anti-Hsp70 (1:1000; sc-24), a mouse anti-Smad4 (1:200; sc-7966), a mouse anti-COX-2 (1:200; sc-19999), a goat antiPUMA (1:200; sc-19190), a mouse anti-p53 (1:1000; sc-126), a mouse anti-EGFR (1:200; sc-03), a mouse anti-cyclin D1 (1:200; sc-20044), or a mouse anti-Mdm2 (1.200; sc-5304), all from Santa Cruz Biotechnology, Santa Cruz, CA, USA. All antibodies were diluted in TBS containing $0.1 \%$ skimmed milk and $0.1 \%$ Tween-20 and incubated at $4{ }^{\circ} \mathrm{C}$ overnight. The membranes were washed and incubated for $1 \mathrm{~h}$ at room temperature with a peroxidase-conjugated anti-mouse $(1: 1500$; P0447, Dako) or a bovine anti-goat antibody (1:1000; sc-2350, Santa Cruz Biotechnology) and the bands were visualized by Western blotting Luminol Reagent (sc-2048, Santa Cruz Biotechnology). Equal loading was verified by reprobing the membrane with a goat anti-actin (I-19; 1:1000; sc-1616, Santa Cruz Biotechnology), followed by a bovine anti-goat antibody (1:1000; sc-2350, Santa Cruz Biotechnology).

The Western blots were carried out at least two times for each protein. One representative blot with bands of good quality both of the selected protein and of actin was chosen as base for further calculations. The film from the selected blot was scanned in an EPSON twain scanner using Adobe Photoshop Ver. 9.0 and the optical density of each protein band was determined with Fuji film Image Gauge Ver. 3.01 software. The optical density of investigated proteins was adjusted to the density of the actin band. The resulting adjusted protein values were then compared using NOK as a baseline, and were designated adjusted relative densitometric (ARD) values. The value in NOK was for all proteins set to 1.0 except for survivin, which is normally not expressed in terminally
Table II. p53 mutations in HNSCC cell lines.

\begin{tabular}{|c|c|c|c|}
\hline Cell line & p53 mutations & Exon & Codon \\
\hline UT-SCC-24A & Splice site mutation ${ }^{\mathrm{a}}$ & 7 & ab 225 \\
\hline UT-SCC-77 & Missense & $5,8,11$ & $179,273,393$ \\
\hline UT-SCC-33 & Missense $^{a}$ & 8 & 282 \\
\hline UT-SCC-34 & Loss of transcript ${ }^{a}$ & $2-11$ & $1-393$ \\
\hline UT-SCC-12A & Missense $^{a}$ & 10 & 342 \\
\hline UT-SCC-2 & Missense $^{a}$ & 8 & 275 \\
\hline UT-SCC-19A & Missense $^{a}$ & 8 & 285 \\
\hline UT-SCC-23 & Loss of transcript ${ }^{\mathrm{a}}$ & $2-11$ & $1-393$ \\
\hline UT-SCC-9 & Loss of transcript ${ }^{\mathrm{a}}$ & $2-11$ & $1-393$ \\
\hline
\end{tabular}

aPreviously reported by Pekkola-Heino et al (18) and Hauser et al (30).

differentiated adult tissue. Therefore, the optical density of the weak survivin band for NOK (Fig. 1B) was determined and after adjustment to actin the value was set to zero. The actin adjusted values of survivin for the nine cell lines were then compared to NOK but using a baseline set to zero. NOK from at least three individuals were used for each protein.

Number of Negative Points. The protein expression (ARD values) of the 14 proteins was classified into four groups 0-3 points; none (0-1.50), small (1.51-4.50), middle (4.51-7.50) or large changes $(\geq 7.51)$ compared to NOK. The 14 proteins were classified in this same point system with the same above levels for the ARD values.

The p53 mutations were arranged into three groups depending on their type. Group one included all mutations, group two contained the splice site and missense mutations and the third group contained loss of transcript (Table II). Each p53 mutation received one point in the NNP system.

\section{Polymerase chain reaction-single strand conformation} polymorphism analysis (PCR-SSCA) and DNA sequencing. Genomic DNA was isolated from the cell samples with the Wizard ${ }^{\circledR}$ Genomic DNA Purification kit according to the supplier's recommendations (Promega, Madison WI, USA). The p53 gene was amplified as described previously by Zhuang et al (25). The PCR reaction consisted of $50 \mathrm{ng}$ DNA, $1.0 \mu \mathrm{M}$ of each primer, $200 \mu \mathrm{M}$ of each dNTP, $2.0 \mathrm{mM}$ $\mathrm{MgCl}_{2}, 20 \mathrm{mM}$ ammonium sulfate, $75 \mathrm{mM}$ Tris $\mathrm{pH} 9.0$, $0.01 \%$ Tween-20 and 0.5 units of ThermoWhite Taq DNA polymerase (Saveen Werner, Sweden) for a total volume of $20 \mu 1$. Amplifications were performed for 35 cycles at $94^{\circ} \mathrm{C}$ for $30 \mathrm{sec}, 55^{\circ} \mathrm{C}$ for $30 \mathrm{sec}$ and $72^{\circ} \mathrm{C}$ for $30 \mathrm{sec}$ in a thermal cycler (PTC 200, MJ Research). Radiolabeling for SSCA was performed in a secondary PCR reaction with nested primers, where $1 \mu \mathrm{l}$ aliquots of the primary PCR reaction were amplified for 8 cycles in the presence of $1.0 \mu \mathrm{Ci}\left[\alpha^{-}{ }^{32} \mathrm{P}\right] \mathrm{dATP}$ $(3000 \mathrm{Ci} / \mathrm{mmol})$. The samples were diluted 1:10 with denaturing gel-loading buffer, denatured at $95^{\circ} \mathrm{C}$ for $5 \mathrm{~min}$ and resolved in $6 \%$ polyacrylamide $/ 5 \%$ glycerol and $0.5 \mathrm{x}$ 
Table III. Protein expression of the Bcl-2 family in HNSCC cell lines.

\begin{tabular}{llllllll}
\hline Cell line & IR & Bcl-2 & Bcl- L & Bax & Bad & Bak & PUMA \\
\hline UT-SCC-24A & 2.6 & 1.21 & $1.53^{\mathrm{a}}$ & $1.8^{\mathrm{a}}$ & 1.0 & 0.86 & 1.0 \\
UT-SCC-77 & 2.5 & 0.35 & $1.88^{\mathrm{a}}$ & $1.98^{\mathrm{a}}$ & $2.17^{\mathrm{a}}$ & 1.16 & $2.01^{\mathrm{a}}$ \\
UT-SCC-33 & 2.3 & 0.36 & 1.22 & $1.87^{\mathrm{a}}$ & $1.52^{\mathrm{a}}$ & 0.93 & 0.55 \\
UT-SCC-34 & 2.1 & $2.98^{\mathrm{a}}$ & $2.51^{\mathrm{a}}$ & $2.58^{\mathrm{a}}$ & $2.76^{\mathrm{a}}$ & 0.84 & 0.54 \\
UT-SCC-12A & 2.1 & 1.04 & $1.56^{\mathrm{a}}$ & $2.29^{\mathrm{a}}$ & $1.46^{\mathrm{a}}$ & 0.97 & 0.13 \\
UT-SCC-2 & 1.8 & 0.96 & 0.18 & $3.92^{\mathrm{a}}$ & 1.29 & 0.65 & $2.09^{\mathrm{a}}$ \\
UT-SCC-19A & 1.7 & 0.78 & $1.88^{\mathrm{a}}$ & 1.15 & 1.30 & 1.32 & $1.74^{\mathrm{a}}$ \\
UT-SCC-23 & 1.6 & 0.94 & $2.62^{\mathrm{a}}$ & $2.33^{\mathrm{a}}$ & $2.37^{\mathrm{a}}$ & 0.93 & $2.97^{\mathrm{a}}$ \\
UT-SCC-9 & 1.4 & 0.52 & 0.48 & 1.22 & 0.95 & 1.24 & 0.73 \\
NOK & & 1.00 & 1.00 & 1.00 & 1.00 & 1.00 & 1.00 \\
\hline
\end{tabular}

Adjusted relative densitometric (ARD) values from Western blot analysis of protein expression of anti- and pro-apoptotic members of the Bcl-2 family. The ARD values were obtained after adjustment to the loading control actin and adjustment to NOK. A value that increased by $50 \%$ (1.5) or more compared to NOK is marked with ${ }^{\text {a }}$.

Mutation Detection Enhancement gels (MDE; FMC BioProducts, Rockland, ME). The fragments were separated at 4-8 watts at room temperature for $16 \mathrm{~h}$. The gels were dried and autoradiographed at $-70^{\circ} \mathrm{C}$ for $5-72 \mathrm{~h}$. PCR products with altered mobility were excised, re-amplified and purified using the ExoSAP-IT enzyme kit (Amersham Biosciences, Uppsala, Sweden). DNA sequencing was performed in both directions using DYEnamic ET Dye Terminator Cycle Sequencing Kit for MegaBACE DNA Analysis Systems (Amersham Biosciences), according to manufacturer's instructions.

Statistical analysis. The correlation between each ARD value with IR, or combinations of ARD values from two or more proteins with the IR of the cell lines, was analyzed with the Pearson's correlation test (2-tailed) using SPSS 12.0.1 for Windows (SPSS Inc.).

A multivariate statistical calculation was carried out to select the combination of factors that had the strongest correlation to IR. The 14 proteins that were expressed and the three groups of p53 mutations were classified using the NNP system. The ARD values were translated into points between zero and three depending on the grade of protein expression. No cell line overexpressed Bak to 50\% more than NOK resulting in its value of zero in the NNP system (Table III). Therefore, only 13 proteins were included in the statistical analyses. The three groups of p53 mutations were all included in the statistical calculation. So, 16 factors, 13 proteins plus three groups of p53 mutations were combined in all possible variants, using a multivariate computer calculation. This calculation gave 65535 different possible combinations of one or more factors. The computer then selected the combination of factors with the strongest correlation to IR.

\section{Results}

EGFR, survivin and $C O X-2$. EGFR is commonly overexpressed in HNSCC and therefore represents a promising therapeutic target. In this study the expression differed greatly among the cell lines and all except UT-SCC-12A expressed more EGFR than NOK. The ARD values ranged from 0.88 (UT-SCC-12A) to 12.32 (UT-SCC-24A; Fig. 1A) and there was no significant correlation $(\mathrm{R}=0.619, \mathrm{P}=0.075)$ between the level of EGFR and the IR of the tumor cell lines. Inhibition of COX-2 in tumor cells has been reported to increase radiosensitivity without influencing normal tissue response to radiation. The expression of COX-2 in these nine cell lines differed extensively and in five of the cell lines COX-2 was overexpressed with ARD values between 2.324.43 (cell line UT-SCC-2, -12A, -23, -24A and -34) but there was again no significant correlation to $I R(R=0.143, P=0.714)$. Survivin, an anti-apoptotic protein, is most often nonexistent in normal cells but is extensively up regulated in tumor cells as it was in all investigated tumor cell lines except UT-SCC-9 (Fig. 1B). Survivin expression did not correlate significantly to IR $(\mathrm{R}=0.494, \mathrm{P}=0.177)$. Since none of these proteins alone showed a significant correlation to IR and the aim was to find the combination of factors that correlated with radiosensitivity, we added the ARD values of EGFR, COX-2 and survivin and this sum had a significant correlation to IR ( $\mathrm{R}=0.825, \mathrm{P}=0.006)$. However, when $\mathrm{COX}-2$ was excluded an even higher correlation was achieved $(\mathrm{R}=0.878, \mathrm{P}=0.002$; Fig. 1C).

The Bcl-2 family. Radio- and chemotherapy resistance is hypothetically due to overexpression of anti-apoptotic proteins like $\mathrm{Bcl}-\mathrm{x}_{\mathrm{L}}$ and $\mathrm{Bcl}-2$ or a decrease in the expression of pro-apoptotic proteins such as $\operatorname{Bax}$, $\operatorname{Bad}, \operatorname{Bak}(5,26)$ and PUMA (6). In this study Bcl-2 was only overexpressed in UT-SCC-34. Bcl- $\mathrm{x}_{\mathrm{L}}$ on the other hand, was up-regulated in six out of nine cell lines (Table III) while Bax, Bad and PUMA were up-regulated in a high number of the cell lines as compared to NOK (Table III). None of these proteins alone showed a significant correlation to IR. Bax, Bad, Bak and PUMA are all thought to be good predictors for treatment and beneficial from a patient perspective. Contrary to $\mathrm{Bcl}-\mathrm{x}_{\mathrm{L}}$ and $\mathrm{Bcl}-2$ they had a negative $\mathrm{R}$ value. Therefore, when the 

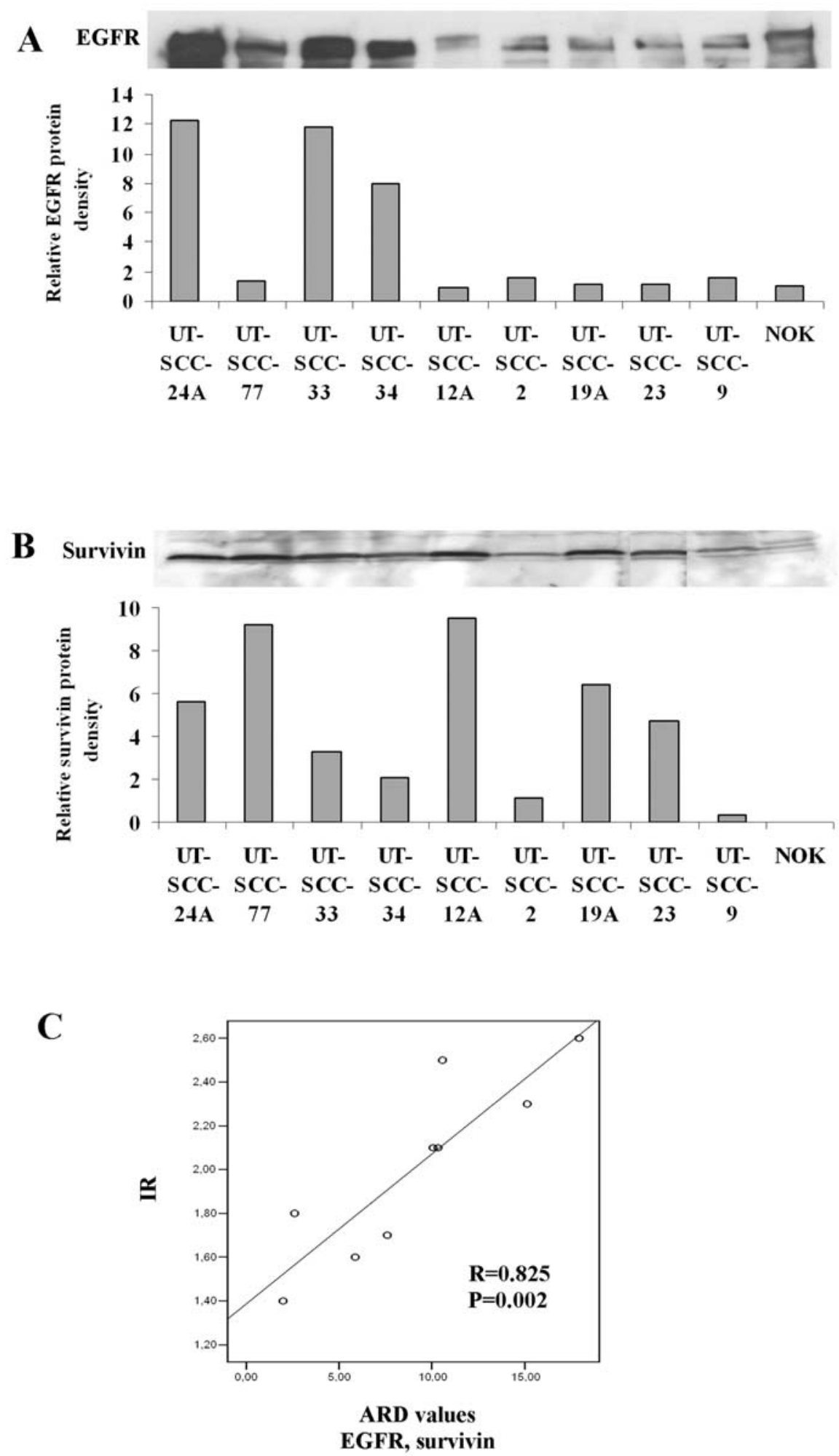

Figure 1. Expression of EGFR and survivin in nine head and neck squamous cell carcinoma (HNSCC) cell lines and in normal oral keratinocytes (NOK). One representative blot out of three is shown. (A) Western blot and adjusted relative densitometric (ARD) values of EGFR expression (NOK=1), (B) Western blot and ARD values of survivin expression $(\mathrm{NOK}=0)$ and $(\mathrm{C})$ Pearson's correlation analysis of the combination of EGFR and survivin and the intrinsic radiosensitivity (IR).

ARD values were added, factors with a negative $R$ value were subtracted from the others. We found a slightly increased correlation to IR $(\mathrm{R}=0.884, \mathrm{P}=0.002)$ when $\mathrm{Bak}$ was subtracted from EGFR and survivin compared to EGFR and survivin alone (Fig. 2A).
Cyclin D1, Smad4 and Hsp70. Cyclin D1 was overexpressed in all investigated cell lines when compared to NOK. Moreover, overexpression of Hsp70 and Smad4 were found respectively in eight and seven of the nine cell lines (Table IV). None of these three factors alone showed a significant correlation to IR. However, when we added these ARD values 


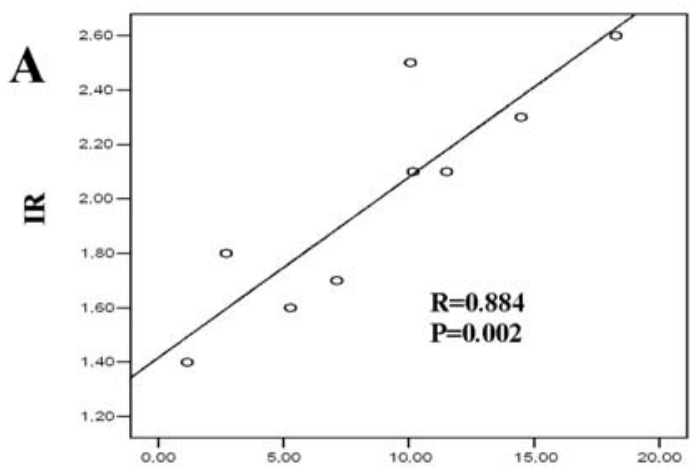

ARD values

EGFR, survivin, Bak

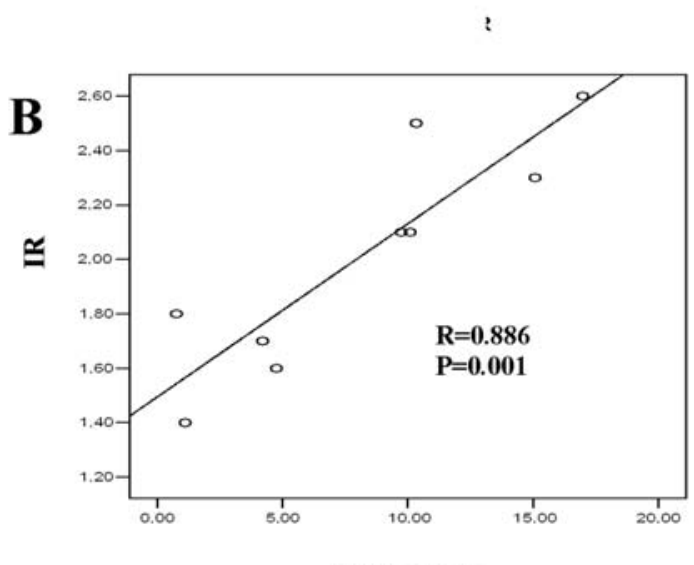

ARD values

EGFR, survivin, Bak, Smad4, Hsp70

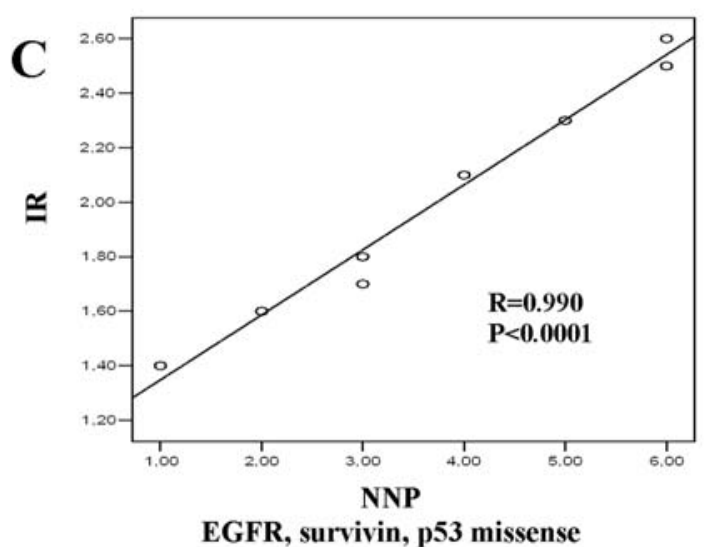

Figure 2. Pearson's correlation analysis of the intrinsic radiosensitivity (IR) and (A) the combination of adjusted relative densitometric (ARD) values for EGFR, survivin and Bak, (B) the combination of ARD values for EGFR, survivin, Bak, Smad4 and Hsp70 and (C) the NNP sum for EGFR, survivin and missense p53 mutations.

together with the values of EGFR, survivin and Bak we found that Hsp70 and Smad4 increased the correlation to IR $(\mathrm{R}=0.886, \mathrm{P}=0.001$; Fig. $2 \mathrm{~B})$.

p53 and its regulator Mdm2. p53 is undoubtedly of great importance in tumorigenesis of many cancer types. We therefore wanted an assessment on both the protein and genetic levels. The analysis displayed p53 changes in all cell lines, although these changes were of different types. The mutation analysis showed one splice site or missense mutation in the p53 gene in five of the nine cell lines and in UT-SCC-77 three p53 mutations were found (Table II). Three of the cell lines had a loss of transcript (exons 2-11; Table II).

Overexpression of the $\mathrm{p} 53$ protein was found in three of the cell lines and the p53 regulator Mdm2 was overexpressed in two of them (Table IV). However, none of these proteins had a significant correlation alone, nor did they improve the correlation to IR together with EGFR, survivin, Bak, Hsp70 and Smad4.

Number of Negative Points. Many biological changes take place during the growth of a tumor. The necessity for and influence of each change is not known. Nor is it known how important one protein expression is compared to another. For this reason we wanted to create a system where both changes in protein expression and genetic alterations could be evaluated and correlated to IR. The classification of protein expression and p53 mutations was named the Number of Negative Points. This name was invented because it describes the combination of different factors that act negatively for the host of the tumor i.e., the patient. In this system, changes of different grades of protein expression are possible to add to the changes on the p53 gene. To create this system we divided the proteins into groups depending on the level of expression. Furthermore, since Western blot is a semi-quantitative method for analyzing protein expression, this grouping also gave a more realistic description of the predictive value of the detected changes. The protein expressions were classified into four groups, 0-3 points; none, small, intermediate or large changes when compared to NOK (see Materials and methods). When the ARD values were translated to the NNP system, Bak did not reach the lower limit for receiving one point. Even though it improved the correlation to IR with ARD values it was not up- or down-regulated enough to receive one point in the NNP system (Table IV) and thus it was not included in the statistical analysis.

The malignant potential of different p53 mutations seems to vary profoundly. We needed to know if there were any differences in correlations to IR depending on what type of p53 mutation a cell line carried. Therefore the p53 mutations were classified into three groups. Group one included all mutations, group two contained the splice site and missense mutations and the third group included loss of transcript, with each mutation receiving one point (see Materials and methods).

In the NNP system there was a statistically significant correlation between the total NNP for all proteins and mutations together and IR $(\mathrm{R}=0.826 ; \mathrm{P}=0.006)$. However, this study aimed at finding the combination of factors that had the strongest correlation to IR. To receive this result we performed a multivariate statistical analysis which combined all factors and then correlated the varying combinations to radiosensitivity. The result from this calculation showed that out of 65535 possible combinations: EGFR, survivin, and the splice site and missense p53 mutations gave the strongest correlation to IR (Table V; Fig. 2C; R=0.990, $\mathrm{P}<0.0001)$. 
Table IV. Protein expression of cyclin D1, Smad4, Hsp70, p53 and Mdm2 in HNSCC cell lines.

\begin{tabular}{|c|c|c|c|c|c|c|}
\hline Cell line & IR & Cyclin D1 & Smad4 & Hsp-70 & p53 & $\mathrm{Mdm} 2$ \\
\hline UT-SCC-24A & 2.6 & $3.85^{\mathrm{a}}$ & $2.72^{\mathrm{a}}$ & 1.43 & 0 & 0.02 \\
\hline UT-SCC-77 & 2.5 & $2.74^{\mathrm{a}}$ & 1.10 & 1.37 & $14.16^{\mathrm{a}}$ & 0.98 \\
\hline UT-SCC-33 & 2.3 & $4.22^{\mathrm{a}}$ & 0.91 & $1.51^{\mathrm{a}}$ & $4.99^{\mathrm{a}}$ & 0.15 \\
\hline UT-SCC-34 & 2.1 & $3.47^{\mathrm{a}}$ & $3.64^{\mathrm{a}}$ & $2.22^{\mathrm{a}}$ & 0.70 & $1.61^{\mathrm{a}}$ \\
\hline UT-SCC-12A & 2.1 & $3.47^{\mathrm{a}}$ & $2.34^{\mathrm{a}}$ & $1.91^{\mathrm{a}}$ & 0.51 & 1.03 \\
\hline UT-SCC-2 & 1.8 & $3.34^{\mathrm{a}}$ & $3.91^{\mathrm{a}}$ & $1.96^{\mathrm{a}}$ & 1.29 & 0.24 \\
\hline UT-SCC-19A & 1.7 & $3.14^{\mathrm{a}}$ & $4.11^{\mathrm{a}}$ & 1.19 & $6.03^{\mathrm{a}}$ & $1.73^{\mathrm{a}}$ \\
\hline UT-SCC-23 & 1.6 & $2.45^{\mathrm{a}}$ & $3.10^{\mathrm{a}}$ & $2.58^{\mathrm{a}}$ & 0.03 & 1.03 \\
\hline UT-SCC-9 & 1.4 & $5.19^{\mathrm{a}}$ & $2.00^{\mathrm{a}}$ & $1.96^{\mathrm{a}}$ & 1.39 & 0.66 \\
\hline NOK & & 1.00 & 1.00 & 1.00 & 1.00 & 1.00 \\
\hline
\end{tabular}

Adjusted relative densitometric (ARD) values from Western blot analysis of protein expression of cyclin D1, Smad4, Hsp70, p53 and Mdm2. The ARD values were obtained after adjustment to the loading control actin and adjustment to NOK. A value that increased by $50 \%$ (1.5) or more compared to NOK is marked with ${ }^{\text {a }}$.

Table V. Number of Negative Points (NNP).

\begin{tabular}{lccccc}
\hline Cell line & IR & EGFR & Survivin & P53-mut & NNP \\
\hline UT-SCC-24A & 2.6 & 3 & 2 & 1 & 6 \\
UT-SCC-77 & 2.5 & 0 & 3 & 3 & 6 \\
UT-SCC-33 & 2.3 & 3 & 1 & 1 & 5 \\
UT-SCC-34 & 2.1 & 3 & 1 & 0 & 4 \\
UT-SCC-12A & 2.1 & 0 & 3 & 1 & 4 \\
UT-SCC-2 & 1.8 & 1 & 1 & 1 & 3 \\
UT-SCC-19A & 1.7 & 0 & 2 & 1 & 3 \\
UT-SCC-23 & 1.6 & 0 & 2 & 0 & 2 \\
UT-SCC-9 & 1.4 & 1 & 0 & 0 & 1 \\
NOK & & 0 & 0 & 0 & 0 \\
\hline
\end{tabular}

\section{Discussion}

The dynamic balance between pro- and anti-apoptotic proteins is believed to be crucial for determining cell fate: survival or cell death. When looking for predictive factors for radiosensitivity, our hypothesis is that the combinations of factors (protein and gene changes) are of great importance for survival of the tumor. In the present study we investigated the expression of 14 proteins and mutations in one gene which are all known to be involved in different parts of the apoptotic or proliferative processes and/or to be expressed in tumor cells. The aim of this study was to find a combination of factors that can predict the outcome of radiotherapy. Therefore, we needed a method where changes in protein expression together with genetic alterations could be compared in the same system and we called this classification the NNP system. In this system we converted the ARD values from Western blot analyses to a classification between zero and three depending on how much protein each cell line expressed compared to NOK. We believe that this gives a more realistic description of the predictive value of the detected protein changes. Even though the studied factors may have differing carcinogenic potential, we made a classification where all factors were presumed to be of equal importance.

Mutations in the p53 gene are thought to have a great impact on carcinogenesis and treatment sensitivity. In this study missense and splice site mutations increased the correlation between NNP and IR, which possibly indicates that a loss of p53 signal can alter the radiosensitivity of HNSCC. The cell line UT-SCC-77 had three missense mutations and therefore got three negative points in the second group. It is not clear whether three missense mutations decreased the radiosensitivity by more than one. Nor is it clear that a very high overexpression of EGFR, as in UT-SCC-24A, decreased the radiosensitivity more than a moderate overexpression. However, our results indicate that both an increased number of missense mutations and a higher expression of EGFR have a negative impact on radiosensitivity.

When using both the NNP system and the ARD values from the Western blot analyses, we found that EGFR and survivin together had a significant correlation to IR. High EGFR expression found in several studies of head and neck cancer has been correlated to poor prognosis, increased risk of metastasis, and advanced tumor stage (9). However, in clinical trials not all patients show an increased survival after blockade of EGFR during radiotherapy, but still the study of Bonner et al showed an increase of both progression-free survival and overall survival of about $10 \%$ (27). To increase the benefit for the patient after blockade of EGFR during radiotherapy, we believe that a more individual selection is needed, and that is where a system like the NNP could be of value. 
Our results show that the total expression of survivin and EGFR were useful predictive factors for radiosensitivity. We found in an earlier study results indicating a role for survivin both in apoptosis and radiosensitivity (23) which we can now confirm.

In this study, none of the investigated members of the Bcl-2 family show a direct relation to radiosensitivity and concerning the correlation to IR, our results indicate that other factors are of greater importance than the Bcl-2 family.

Using ARD values, Smad4 increased the correlation to IR when added to EGFR, survivin and Bak. A majority of described mutations in the SMAD4 tumor suppressor gene in HNSCC are missense mutations outside codon 330-370, which inactivate $\mathrm{Smad} 4$ by protein degradation (28). Surprisingly, in this study Smad4 was detected in all cell lines and its increased expression compared to NOK was detected in seven of nine cell lines. When using the NNP system the correlation to IR was not improved either by Smad4 or by the anti-apoptotic protein Hsp70.

A great problem in clinical work is the varying response to radiotherapy. Some HNSCC even grow during ongoing radiotherapy, and it would be of interest from both the socioeconomic point of view and from that of the patient to only give effective treatment. In order to do this, it is necessary to understand the changes that are responsible for the process of tumor progression. Theoretically, a large number of factors affecting growth control, apoptosis and other processes could be altered, which is why the recognition of a panel of multiple predictive factors is of great importance. Our long-term goal is to identify markers in a newly found tumor, to help clinicians predict the most effective treatment in each patient. More studies are needed to analyze factors that were not included in this study. It would be of interest to verify the NNP correlation to IR in a greater number of samples and with more quantitative methods like ELISA or RT-PCR.

Taken together, we created a classification where the NNP for three factors gives a combination that correlates significantly to the previously known IR. Most likely, there are other factors that play an important role in tumor radiosensitivity and of course the results must be interpreted with care, as there are many proteins involved in apoptosis and proliferation not represented in this study. Even so we introduce a new method of predicting radiosensitivity when combining 3 of 17 factors.

In conclusion, when further evaluated, the present novel method could give an effective approach towards the optimization for treatment in HNSCC.

\section{Acknowledgements}

We thank Olle Eriksson, PhD, Department of Mathematics, Division of Statistics, University of Linköping, Sweden, for assistance with the computer-based multivariate statistical analyses. This study was supported by the Swedish Laryng Foundation, the County Council of Östergötland (ÖLL), the Research Council of South Eastern Sweden (FORSS), Gunnar Nilsson's Cancer foundation, and The Swedish Cancer foundation (No. 070180), The Swedish Society of Medicine and from the Research Funds of Linköping University Hospital.

\section{References}

1. Haffty BG and Glazer PM: Molecular markers in clinical radiation oncology. Oncogene 22: 5915-5925, 2003.

2. Lothaire P, De Azambuja E, Dequanter D, et al: Molecular markers of head and neck squamous cell carcinoma: promising signs in need of prospective evaluation. Head Neck 28: 256-269, 2006.

3. Zhan Q, Bae I, Kastan MB and Fornace AJ Jr: The p53dependent gamma-ray response of GADD45. Cancer Res 54: 2755-2760, 1994.

4. Condon LT, Ashman JN, Ell SR, Stafford ND, Greenman J and Cawkwell L: Overexpression of Bcl-2 in squamous cell carcinoma of the larynx: a marker of radioresistance. Int $\mathbf{J}$ Cancer 100: 472-475, 2002.

5. Guo B, Cao S, Toth K, Azrak RG and Rustum YM: Overexpression of Bax enhances antitumor activity of chemotherapeutic agents in human head and neck squamous cell carcinoma. Clin Cancer Res 6: 718-724, 2000.

6. Yu J, Yue W, Wu B and Zhang L: PUMA sensitizes lung cancer cells to chemotherapeutic agents and irradiation. Clin Cancer Res 12: 2928-2936, 2006

7. Ang KK, Berkey BA, Tu X, et al: Impact of epidermal growth factor receptor expression on survival and pattern of relapse in patients with advanced head and neck carcinoma. Cancer Res 62: 7350-7356, 2002

8. Eriksen JG, Steiniche T, Askaa J, Alsner J and Overgaard J: The prognostic value of epidermal growth factor receptor is related to tumor differentiation and the overall treatment time of radiotherapy in squamous cell carcinomas of the head and neck. Int $\mathbf{J}$ Radiat Oncol Biol Phys 58: 561-566, 2004.

9. Hitt R, Ciruelos E, Amador ML, et al: Prognostic value of the epidermal growth factor receptor (EGRF) and p53 in advanced head and neck squamous cell carcinoma patients treated with induction chemotherapy. Eur J Cancer 41: 453-460, 2005.

10. Dubois RN, Abramson SB, Crofford L, et al: Cyclooxygenase in biology and disease. FASEB J 12: 1063-1073, 1998.

11. Jones MK, Wang H, Peskar BM, et al: Inhibition of angiogenesis by non-steroidal anti-inflammatory drugs: insight into mechanisms and implications for cancer growth and ulcer healing. Nat Med 5: 1418-1423, 1999

12. Thomas GR, Nadiminti H and Regalado J: Molecular predictors of clinical outcome in patients with head and neck squamous cell carcinoma. Int J Exp Pathol 86: 347-363, 2005.

13. Deveraux QL and Reed JC: IAP family proteins - suppressors of apoptosis. Genes Dev 13: 239-252, 1999.

14. Altieri DC: Survivin, versatile modulation of cell division and apoptosis in cancer. Oncogene 22: 8581-8589, 2003.

15. Lo Muzio L, Pannone G, Staibano S, et al: Survivin expression in oral squamous cell carcinoma. Br J Cancer 89: 2244-2248, 2003.

16. Garrido C, Brunet M, Didelot C, Zermati Y, Schmitt E and Kroemer G: Heat shock proteins 27 and 70: anti-apoptotic proteins with tumorigenic properties. Cell Cycle 5: 2592-2601, 2006.

17. Grady WM: Transforming growth factor-beta, Smads and cancer. Clin Cancer Res 11: 3151-3154, 2005.

18. Pekkola-Heino K, Jaakkola M, Kulmala J and Grenman R: Comparison of cellular radiosensitivity between different localizations of head and neck squamous-cell carcinoma. J Cancer Res Clin Oncol 121: 452-456, 1995.

19. Sundqvist K, Liu Y, Arvidson K, et al: Growth regulation of serum-free cultures of epithelial cells from normal human buccal mucosa. In Vitro Cell Dev Biol 27A: 562-568, 1991.

20. Grenman R, Burk D, Virolainen E, et al: Clonogenic cell assay for anchorage-dependent squamous carcinoma cell lines using limiting dilution. Int J Cancer 44: 131-136, 1989.

21. Erjala K, Pulkkinen J, Kulmala J and Grenman R: Concomitant vinorelbine and radiation in head and neck squamous cell carcinoma in vitro. Acta Oncol 43: 169-174, 2004.

22. Fertil B, Dertinger H, Courdi A and Malaise EP: Mean inactivation dose: a useful concept for intercomparison of human cell survival curves. Radiat Res 99: 73-84, 1984.

23. Roberg K, Jonsson AC, Grenman R and Norberg-Spaak L: Radiotherapy response in oral squamous carcinoma cell lines: evaluation of apoptotic proteins as prognostic factors. Head Neck 29: 325-334, 2007.

24. Lowry OH, Rosebrough NJ, Farr AL and Randall RJ: Protein measurement with the Folin phenol reagent. J Biol Chem 193: 265-275, 1951. 
25. Zhuang SM, Cochran C, Goodrow T, Wiseman RW and Soderkvist P: Genetic alterations of p53 and ras genes in 1,3butadiene- and 2',3'-dideoxycytidine-induced lymphomas. Cancer Res 57: 2710-2714, 1997.

26. Reed JC: Bcl-2 family proteins. Oncogene 17: 3225-3236, 1998.

27. Bonner JA, Harari PM, Giralt J, et al: Radiotherapy plus cetuximab for squamous-cell carcinoma of the head and neck. $\mathrm{N}$ Engl J Med 354: 567-578, 2006.

28. Iacobuzio-Donahue CA, Song J, Parmiagiani G, Yeo CJ, Hruban RH and Kern SE: Missense mutations of MADH4: characterization of the mutational hot spot and functional consequences in human tumors. Clin Cancer Res 10: 1597-1604, 2004.
29. Erjala K, Pulkkinen J, Kulmala J, Alanen K and Grenman R: Head and neck squamous cell carcinoma is highly sensitive to vinorelbine in vitro. Anticancer Res 22: 3135-3142, 2002.

30. Hauser U, Balz V, Carey TE, et al: Reliable detection of p53 aberrations in squamous cell carcinomas of the head and neck requires transcript analysis of the entire coding region. Head Neck 24: 868-873, 2002. 